TITLE:

\title{
A geochemical clogging model with carbonate precipitation rates under hydrothermal conditions
}

\section{$\operatorname{AUTHOR}(\mathrm{S})$ :}

Yoo, Seung-Youl; Kuroda, Yoshihiro; Mito, Yoshitada; Matsuoka, Toshifumi; Nakagawa, Masami; Ozawa, Akiko; Sugiyama, Kazutoshi; Ueda, Akira

\section{CITATION:}

Yoo, Seung-Youl ...[et al]. A geochemical clogging model with carbonate precipitation rates under hydrothermal conditions. Applied Geochemistry 2013, 30: 67-74

\section{ISSUE DATE:}

2013-03

URL:

http://hdl.handle.net/2433/173707

\section{RIGHT:}

(C) 2012 Elsevier Ltd.; This is not the published version. Please cite only the published version.; この論文は出版社版でありません。引用の際に は出版社版をご確認ご利用ください。 


\title{
A geochemical clogging model with carbonate precipitation rates under hydrothermal conditions
}

Seung-Youl Yoo a,", Yoshihiro Kuroda ${ }^{\text {a, }{ }^{* *},}$, Yoshitada Mito ${ }^{a}$, Toshifumi Matsuoka ${ }^{a}$, Masami Nakagawa ${ }^{\mathrm{b}}$, Akiko Ozawa $^{\mathrm{c}}$, Kazutoshi Sugiyama $^{\mathrm{c}}$ and Akira Ueda ${ }^{\mathrm{d}}$

a: Graduate School of Engineering, Kyoto University, Kyotodaigaku-Katsura, Nishikyo-ku, Kyoto, 615-8540 Japan

b: Department of Mining Engineering, Colorado School of Mines, 1500 Illinois Street, Golden, Colorado, 80401 USA

c: Department of Natural Resources and Environment, Mitsubishi Materials Techno Corp., 1297 Kitabukuro, Saitama, 330-0835 Japan

d: Graduate School Division of Science and Engineering, University of Toyama, Gofuku 3190, Toyama, 930-8555 Japan

* Corresponding author; s_ryu@earth.kumst.kyoto-u.ac.jp

** Present address; Subsurface Evaluation Unit of Technical Division, INPEX Corp., 5-3-1 Akasaka, Minato-ku, Tokyo, 107-6332 Japan

\begin{abstract}
A step-wise numerical calculation method was developed to provide predictions of when and where carbonate deposits might be found through reservoirs during $\mathrm{CO}_{2}$ sequestration. Flow experiments through porous media using a supersaturated carbonate fluid were also performed in order to observe flow rates. In order to evaluate precipitation rates and permeability change in the formation, calculated flow rates based on the proposed geochemical clogging model were compared with the experimentally observed data. Both high and low temperature cases were studied to understand how hydrothermal conditions can affect precipitation rates of carbonate. According to chemical kinetics, growth rates of minerals are generally proportional to the saturation index (S.I.) that depends on temperature. Thus, a supersaturated fluid has the advantage of improving the filtration and the amount of $\mathrm{C}$ fixation $(\sigma)$. However, when the ratio of filtration coefficient $(\lambda)$ to pore fluid velocity $(u)$ increases, the permeability around the injection point tends to be significantly reduced by carbonate accumulation, and thus, this might result in insufficient injection of $\mathrm{CO}_{2}$. Therefore, it is essential to understand how to control both $\lambda$ and $u$ so that the precipitation of carbonate can be located as far away from the inlet as possible.
\end{abstract}

\section{Introduction}

Carbonate mineralization takes advantage of permeability reduction to seal formations with a decreasing risk of $\mathrm{CO}_{2}$ leakage while increasing storage safety. It has been experimentally shown that the calcite- and kaolinite- rich rock produced through $\mathrm{CO}_{2}$-water-rock interaction (Gales and Shane, 1905; Gunter and Bird, 1988) clog pores or fractures in the $\mathrm{CO}_{2}$ reservoir (Lee et al., 1996). Precipitation rates tend to be faster at higher temperatures and the solubility product shows lower values (Chiba, 1991). Long-term $\mathrm{CO}_{2}$ containment and safety evaluation of $\mathrm{CO}_{2}$ leakage are important issues, making regions that have thick and continuous cap rock more attractive as storage locations.

A single reservoir measurement at Sleipner indicates a temperature at the injection point of 
about $36{ }^{\circ} \mathrm{C}$. Under such conditions, $\mathrm{CO}_{2}$ will remain stable as a supercritical phase due to slow reaction rates in reservoir rocks (Bickle et al., 2007). On the other hand, at the Nagaoka site, although the injected $\mathrm{CO}_{2}$ was in a supercritical state under the temperature of formation water $\left(48.8^{\circ} \mathrm{C}\right)$, the observed chemical composition of water and the reservoir modeling indicated that mineral trapping would be more important than at Sleipner as geologic sequestration could occur from the early stage of $\mathrm{CO}_{2}$ storage (Mito et al., 2008). The precipitation kinetics of calcite used by Mito et al. (2008) were those examined (Brown et al., 1993; Jonasson et al., 1996; Teng et al., 2000; Zhang and Dawe, 2000) and fitted to second order expressions at elevated temperatures (Shiraki and Brantley, 1995).

Meanwhile, it is known that the rate of chemical reaction rate of $\mathrm{CO}_{2}$ with the rock becomes faster and the carbonate minerals precipitate easily as the reaction temperature rises. Carbon dioxide reacts with $\mathrm{Ca}$ from the rock, and carbonate will be formed as $\mathrm{CO}_{2}$ is fixed when the exhaust gas is injected into the high-temperature underground region (Ozawa et al., 2006; Kuroda et al., 2009). The basic idea of this research is to study acceleration in growth of the artificial carbonate, which can prevent $\mathrm{CO}_{2}$ from leaking and facilitate $\mathrm{CO}_{2}$ storage in areas with no continuous cap rock. In contrast to the benefit of self-sealing by calcite, injectivity might decrease with time due to reservoir clogging. Filtration is a key concept to explain the mechanism by which very small mineral particles are transported through carbonate fluid and are extracted from solution by chemical reaction between fluid and rocks. Calcium ions released from rocks might be removed as $\mathrm{CaCO}_{3}$ during $\mathrm{CO}_{2}$ injection into relatively high-temperature fields (Ueda et al., 2005).

The carbonate mineral formed in ultramafic rocks is commonly hydromagnesite at low temperature (RITE, 2008) and calcite at high temperature in the Ogachi Hot Dry Rock (HDR) geothermal site (Kaieda et al., 2005). However, there is little information on how permeability changes in reservoirs by chemical reaction of $\mathrm{CO}_{2}$ with reservoir rocks.

For this reason, a newly developed clogging model is used to evaluate rates and amounts of carbonate precipitation by monitoring flow rates during $\mathrm{CO}_{2}$ sequestration. Results of laboratory scale experiments and numerical simulations can provide insights for clogging phenomena in low permeability reservoirs by carbonate deposition with respect to location and time.

\section{Experimental setup}

Column tests were performed in order to evaluate the precipitation rates of carbonate minerals such as calcite and permeability change, using two types of porous media (glass beads and rock cuttings) and different fluid properties. The chemical compositions of solutions were determined by ICP-MS (for $\mathrm{Mn}, \mathrm{Fe}$ and $\mathrm{Al}$ ) ICP-AES (for $\mathrm{Na}, \mathrm{K}, \mathrm{Ca}$ and $\mathrm{Mg}$ ) and ion chromatography (for $\mathrm{Cl}$ and $\mathrm{SO}_{4}$ ) (Table 1). The saturation index (S.I.) values with respect to calcite were calculated from equation (1):

$$
\text { S.I. }=\log \left(\frac{\text { I.A.P. }}{K_{s p}}\right)
$$

where I.A.P. and $K_{s p}$ are ion activity products and solubility products of calcite, respectively. The fluid is supersaturated with respect to calcite (S.I. > 0) so precipitation of calcite will occur. 


\subsection{Column test at room temperature (for Namikata LPG site)}

The groundwater which was used for the column test was obtained from a tunnel at the Namikata LPG stockpiling base in Ehime Prefecture, Japan. This water is enriched in $\mathrm{CaCO}_{3}$ and has a high $\mathrm{pH}$ due to interaction with cement $(\mathrm{pH}=11.3$ and S.I.=1.1), resulting in calcite precipitation in the tunnel. The test with this groundwater was performed at constant average temperature $\left(20.2^{\circ} \mathrm{C}\right)$ for 25 days. The equipment setup was designed to maintain the deferential total head $(\Delta h=100 \mathrm{~cm})$ by keeping the points of overflow and discharge fixed as shown in Figure 1(a). The fluid was injected into the column at $13.3 \mathrm{~cm}^{3} / \mathrm{s}$ initially. The column is a rectangular, parallel piped chamber with $50-\mathrm{cm}$-long sides and $4 \mathrm{~cm}$ square on the side. The column is packed with glass beads, which have as average diameter of $2 \mathrm{~mm}$ and a density of $2.50 \mathrm{~g} / \mathrm{cm}^{3}$. The initial porosity of this packed column was 0.29 , which was determined by the volume of water in pores and the volume of the column. For numerical simulations, it is appropriate to adopt glass beads because they are spherical shapes and density is almost the same as the rock. Both top and bottom of the column are covered with filters to render the glass beads immovable.

\subsection{Column test at high temperature (at Ogachi HDR geothermal site)}

The laboratory experiment was performed under conditions similar to Ogachi HDR geothermal site, Japan. The equipment setup is illustrated in Figure 1(b). The column consists of a cylindrical chamber with an inside diameter of $4 \mathrm{~cm}$ and the height of $50 \mathrm{~cm}$. A section of granodiorite core (from $998 \mathrm{~m}$ depth in the Ogachi production well) was crushed and sieved to 1-2 mm diameter. These rock fragments, the density of which is $2.66 \mathrm{~g} / \mathrm{cm}^{3}$, were packed into the column. The porosity of the column with rock cuttings was measured at 0.27 , which was also the volume of saturated water in the closed-packing column. The injection pipe was positioned at the top of the column and fluid at neutral $\mathrm{pH}(=6.2)$ flowed downward at an initial flow rate of $5.5 \mathrm{~cm}^{3} / \mathrm{s}$ for 4 days. Flow rates, temperature, and pressure within the column were monitored every hour. The differential total head between the inlet and the outlet was $5 \mathrm{kPa}$ regarded as a 50-cm-length column. Before injecting the fluid into the column, the S.I. with respect to calcite was -0.38 (dissolution of calcite) at $15.1^{\circ} \mathrm{C}$. After injecting the fluid into the heating column, S.I. increased by 1.8 when the average temperature was kept constant at $185^{\circ} \mathrm{C}$. Fluid pressure inside the column increased from $2 \mathrm{MPa}$ to $6 \mathrm{MPa}$ gradually.

\section{Geochemical clogging model}

\subsection{Advection-reaction equation}

As is well known, the calcite deposits are represented as a two-component system of $\mathrm{Ca}^{2+}$ and $\mathrm{CO}_{3}{ }^{2-}$ as shown in equation (2).

$$
\mathrm{CaCO}_{3}=\mathrm{Ca}^{2+}+\mathrm{CO}_{3}{ }^{2-}
$$

The rate of calcite precipitation is regulated by both changes in $\mathrm{Ca}^{2+}$ and $\mathrm{CO}_{3}{ }^{2-}$ concentration in the fluid. Bicarbonate is a major species in neutral solutions. The equilibrium conditions in equation (2), which also thermodynamically represents the real reaction, were calculated. For this reason, the precipitation rate is replaced as a one-component fluid with $\mathrm{Ca}^{2+}$ for convenience. When the concentration of $\mathrm{Ca}$ is less than that of $\mathrm{CO}_{3}$ for example in the case of 
Namikata, the amount of deposited Ca might be overestimated.

In this calculation, the conservation of mass for one-dimensional transport with calcite deposition in porous media (Fig. 2) is modeled by an advection-reaction formulation as in equation (3) (Parkhurst and Appelo, 1999; Shikazono et al., 2009):

$$
\frac{\partial C}{\partial t}=-u \frac{\partial C}{\partial x}-k_{T}\left(\frac{A}{M}\right)\left(\frac{C-C_{e q}}{C_{e q}}\right)
$$

where $C$ is the $\mathrm{Ca}^{2+}$ concentration in flowing water $\left(\mathrm{g} / \mathrm{cm}^{3}\right), C_{e q}$ is the equilibrium $\mathrm{Ca}^{2+}$ concentration in water $\left(\mathrm{g} / \mathrm{cm}^{3}\right)$, which is temperature dependent, $t$ is time $(\mathrm{s}), u$ is the fluid velocity in porous media $(\mathrm{cm} / \mathrm{s}), x$ is distance $(\mathrm{cm}), A / M$ is the specific reactive surface area $(A)$ per kg of $\mathrm{H}_{2} \mathrm{O}(M)$, and $k_{T}\left(\mathrm{~mol} \cdot \mathrm{cm}^{-2} \cdot \mathrm{s}^{-1}\right)$ is the rate constant of the chemical reaction at $T$, which can be shown as a function of temperature by the Arrhenius equation (4):

$k_{T}=k_{25} \exp \left[\frac{-E_{a}}{R}\left(\frac{1}{T}-\frac{1}{298.15}\right)\right]$

where $E_{a}$ is the activation energy, $R$ is the gas constant, $T$ is the absolute temperature, and $k_{25}$ is the rate constant at $298.15 \mathrm{~K}$.

In the case of steady state flow when concentrations of $\mathrm{Ca}^{2+}$ and $\mathrm{CO}_{3}{ }^{2-}$ are constant, the general solution of equation (3) can be described by equation (5) when the concentration at the inlet $(x=0)$ equals the influent concentration $\left(C_{i}{ }^{\prime}\right)$ :

$C^{\prime}=C_{i}^{\prime} \exp \left[-\left(\frac{k_{T} A}{C_{e q} M}\right)\left(\frac{x}{u}\right)\right]$

where $C^{\prime}\left(=C-C_{e q}\right)$ is the supersaturated concentration if S.I. > 0. Introducing the filtration coefficient $(\lambda)$ as $\lambda=\left(k_{T} / C_{e q}\right) \cdot(A / M)$, equation (5) can be rewritten by equation (6).

$$
C^{\prime}=C_{i}^{\prime} \exp \left[-\frac{\lambda}{u} x\right]
$$

From equation (2), the solubility product constant for calcite in the water is a function of temperature, as shown in equation (7) (Arnórsson et al., 1982).

$$
K_{s p}=10.22-0.0349 T-2476 / T
$$

The concentration of $\mathrm{Ca}^{2+}$ is assumed to be nearly equal to that of $\mathrm{CO}_{3}{ }^{2-}$, and the equilibrium concentration of $\mathrm{Ca}^{2+}$ can be calculated by equation (8).

$$
C_{e q}=\sqrt{K_{s p}}=\sqrt{10.22-0.0349 T-2476 / T}
$$

Finally, temperature dependent precipitation rates of calcite $\left(v_{n}\right)$ as $k_{T} / C_{e q}$ become equation (9).

$$
v_{n}=\frac{k_{25} \exp \left[\frac{-E_{a}}{R}\left(\frac{1}{T}-\frac{1}{298.15}\right)\right]}{\sqrt{10.22-0.0349 T-2476 / T}}
$$

This calcite precipitation causes the fluid flow to clog in porous media and the aim of the study is to investigate the change of the precipitation rates caused by flow conditions. In the two experiments mentioned above it was observed that clogging decreases the permeability of porous media and leads to reducing amounts of flow. From equation (9) the precipitation of calcite is controlled not only by the rate constant of the chemical reaction $\left(k_{25}\right)$ but also by 
temperature $(T)$. In the following sections an estimation method of $k_{25}$ values will be proposed from observed data sets.

\subsection{Calculation procedure}

Step-wise numerical calculation was programmed by spread sheet for the geochemical clogging model. This model takes into account various properties given by the experimental conditions (Table 2$)$ and it can evaluate the amount of $\mathrm{Ca}\left(\sigma_{i, j}\right)$, flow rates $\left(Q_{i, j}\right)$ and precipitation rates $\left(v_{n}\right)$. These properties can be assumed to be constant within a small discretized grid for computational purposes in each step following the procedure in Figure 3. The subscripts $i$ and $j$ represent the space grid index and the time index, respectively.

In the laboratory experiments, flow rates $\left(Q_{i, j}\right)$ are monitored with elapsed time to predict precipitation rates $\left(v_{n}\right)$. The trial-and-error approach was adopted in order to estimate $k_{25}$ from obtained data sets; given appropriate initial $k_{25}$ value, the various factors (e.g., pore fluid velocity $\left(u_{i, j}\right)$, supersaturated concentration $\left(C_{i, j}^{\prime}\right)$, amount of deposited $\mathrm{Ca}\left(\sigma_{i, j}\right)$, porosity $\left(n_{i, j}\right)$ and intrinsic permeability $\left(K_{i, j}\right)$ ) can be estimated step by step by using the computational procedure in Figure 3. Applying Darcy's law to the column tests, the porosity-intrinsic permeability relationship is assumed to obey the Kozeny-Carman equation (Carrier, 2003). It is possible to obtain the change of flow rates with updated intrinsic permeability for a given rate constant $k_{25}$. Details of the computational steps are as follows.

The pore fluid velocity $\left(u_{i, j}\right)$ can be expressed as equation (10):

$u_{i, j}=K_{i, j} \cdot i_{i, j} / n_{i, j}$

where $i_{i, j}$ is hydraulic gradient, $K_{i, j}$ and $n_{i, j}$ are intrinsic permeability and porosity of the porous media, respectively. The initial intrinsic permeability $\left(K_{i, 0}\right)$ was calculated with initial flow rates $\left(Q_{i, 0}\right)$ and the initial porosity is given by the laboratory measurement in Table 2 . Although the concentration of $\mathrm{Ca}^{2+}$ decreases exponentially with the distance of fluid flow, it is assumed that this value is constant within the infinitesimal grid elements. The supersaturated concentration in the zone between $x_{i-1}$ and $x_{i}$ during $\Delta t$ can be expressed as equation (11):

$$
C_{i, j}^{\prime}=C_{i-1, j}^{\prime} \exp \left[\frac{-\lambda\left(x_{i}-x_{i-1}\right)}{2}\left(\frac{1}{u_{i-1, j}}+\frac{1}{u_{i, j}}\right)\right]
$$

This precipitation process has been described as the first-order rate law from previous filtration studies (Ives, 1975; Gruesbeck and Collins, 1982; Kim et al., 2009) as equation (12):

$$
\frac{\partial \sigma_{i, j}}{\partial t}=\lambda C_{i, j}^{\prime}
$$

Then, the total amount of deposited $\mathrm{Ca}$ is expressed as the cumulative amount of deposits in equation (13).

$$
\sigma_{i, j}=\sum_{j=1}^{j} \Delta \sigma_{i, j}=\sum_{j=1}^{j} \lambda C_{i, j}^{\prime} \Delta t
$$

This deposited Ca changes the porosity. The porosity at position $i$ and time step $j+1$ is updated to equation (14):

$$
n_{i, j+1}=n_{0}-\frac{n_{i, j} \sigma_{i, j}}{\rho_{s}}
$$


which can be simplified to equation (15) when assuming $n_{i, j}$ is approximately equal to $n_{i, j+1}$ :

$n_{i, j+1}=\frac{n_{0}}{1+\sigma_{i, j} / \rho_{s}}$

where $n_{0}$ is the initial porosity ( 0.29 in the Namikata case, 0.27 in the Ogachi case) and $\rho_{s}$ is the density of $\mathrm{Ca}$. Based on the Kozeny-Carman equation with porosity change, the intrinsic permeability at time step $j+1$ is updated as equation (16) at all space grid points $i$ :

$$
K_{i, j+1}=K_{i, j}\left(\frac{n_{i, j+1}}{n_{i, j}}\right)^{3}\left(\frac{1-n_{i, j}}{1-n_{i, j+1}}\right)^{2}
$$

As described above, the proposed geochemical model is applicable to supersaturation cases for $\mathrm{CaCO}_{3}$ because the change of porosity resulting from the precipitation process is taken into consideration. Decrease of pore fluid velocity caused by calcite precipitation accounts for the reduction of flow rates. Finally, the calculated flow rates, as per equation (17), can be matched to observed data in column tests in order to evaluate precipitation rates:

$Q_{i, j}=u_{i, j} \cdot n_{i, j} \cdot A$

where $A$ is the cross-sectional area of the column packed with porous media. If these observed and calculated flow rates have a large discrepancy, the rate constant $\left(k_{25}\right)$ assumed initially is modified until these values become close enough.

\section{Results and discussion}

Column tests were performed at a low temperature $\left(20.2^{\circ} \mathrm{C}\right)$ for Namikata and at a high temperature $\left(185^{\circ} \mathrm{C}\right)$ for Ogachi. Even though both experiments used material and fluid that had different properties, discussion focuses on clogging mechanisms with permeability changes.

Deposits of both calcite and portlandite $\left(\mathrm{Ca}(\mathrm{OH})_{2}\right)$, identified by X-ray diffraction (XRD), were found on the surface of rock cuttings in the column test at Ogachi. Portlandite which precipitated in the center part of the column might affect the observed permeability change. In contrast, calcite was distributed uniformly. From this observation, the estimated precipitation rates of $\mathrm{Ca}$ minerals include both portlandite and calcite. Controlling temperature was difficult in this experiment and may have exceeded $250{ }^{\circ} \mathrm{C}$ temporarily. The solubility of calcite decreases with increasing temperature and precipitation occurs immediately at high temperatures. In addition, the variations in temperature inside the column would impact precipitation rates as more clogging would occur in elevated temperature sections.

Properties of porous material and fluid are listed in Table 2 as experimental conditions. The required specific reactive surface area $(A / M)$ and activation energy $\left(E_{a}\right)$ are given as $9.8 \mathrm{~cm}^{2} / \mathrm{g}$ and $41.87 \mathrm{~kJ} / \mathrm{mol}$, respectively, in Table 2 (Xu et al., 2004). The proposed methodology in this model can estimate the change of total head, pore fluid velocity and porosity with respect to the distance from the inlet (Figs 4 and 5). When the pore fluid velocity decreases with time elapsed, the constant filtration coefficient divided by pore fluid velocity increases and the distribution of Ca concentration is likely to decline drastically.

Previous research has had limitations for evaluating where and when clogging could be either an advantage or a problem. Thus, the present numerical modeling developments are more applicable to simulate permeability change during $\mathrm{CO}_{2}$ storage. The results of numerical 
calculations indicate that dissolved $\mathrm{CO}_{2}$ can be fixed as carbonate at both high temperatures and low temperatures. In this respect, several applications such as geothermal power plants and facilities for propane storage are favorable for quick mineralization to contribute to industrial application on storage safety. According to kinetic theory, precipitation rates tend to be greater with decreasing solubility product constant at high temperature. Equation (9), however, implies that precipitation rates can be accelerated with the high-rate constant $k_{25}$ even if the temperature is low. Even though the Namikata case might be inappropriate to $\mathrm{CO}_{2}$ sequestration due to scale problems around the borehole, the carbonate mechanism at low temperature is worth comparing to the neutral mechanism for the Ogachi case, if only as a modeling validation exercise.

The amount of precipitation with respect to distance is distributed quite uniformly in Ogachi, but calcite accumulated close to the inlet in Namikata (Fig. 6a). In the case of Namikata, the amount of $\mathrm{C}$ fixation as a solid phase was limited due to the fact that the supersaturated fluid could not flow into deeper parts of porous media due to the accumulation of suspended calcite particles occurring around the inlet (Fig. 6b). In this respect, the conditions at Ogachi fit better than the Namikata case in mineral trapping for sustainable carbonate storage (Fig. 6c).

Figure 7 shows the normalized intrinsic permeability distribution with space and time. Intrinsic permeability for the Namikata case decreased markedly below $x<20 \mathrm{~cm}$ and thereafter kept constant and almost the same as the initial intrinsic permeability in the remaining column section (Figs. 7a and b). These results are consistent with carbonate accumulation around the inlet (Fig. 6a). In contrast, the intrinsic permeability for the Ogachi case showed more uniform distribution at any distance from the inlet as shown in Figure $7 \mathrm{c}$. The value $\lambda / u$ is a key parameter to explain clogging phenomena with chemical reaction and advection. The smaller the $\lambda u$, the more it is possible for geochemical trapping to deposit uniformly, as in the Ogachi case. In this respect, optimal $\lambda / u$ can lead to successful $\mathrm{CO}_{2}$ fixation at hydrothermal conditions.

\section{Conclusions}

Precipitation rates for calcite accelerate with not only increasing temperature but also alkali concentrations even in the case of low temperatures. From this point of view, a step-wise numerical simulation has been developed considering filtration and advection including for systems at high and low temperatures. The possible amount of deposited $\mathrm{Ca}$ as calcite was evaluated for sustainable mineral trapping in $\mathrm{CO}_{2}$ sequestration considering the effect of clogging phenomena. In the case of one-dimensional flow, the concentration for advectionreaction was derived by a mass balance equation and the first-order filtration law. In addition, the rate constant of the chemical reaction was used to predict permeability change with respect to time scales. Two column tests have been carried out in order to verify the geochemical clogging model proposed in this paper. Calculation indicate controlling the value of $\lambda / u$ becomes the key parameter for successful $\mathrm{CO}_{2}$ sequestration.

\section{Acknowledgements}

We appreciate the comments of Dr. Chris Rochelle and an anonymous reviewer, both of which helped to improve the manuscript. This study partly consists of the project "Development of Technologies to Directly Fix Carbon Dioxide from Flue Gas in Geological Formation with GEOREACTOR" funded by the Ministry of Economy, Trade and Industry of Japan (METI). We gratefully acknowledge all members of the Georeactor group for their helpful assistance and 
comments. The authors (T.M., S.Y.Y., Y.M., A.U.) acknowledge JST/ JICA, SATREPS for supporting this research.

\section{References}

Arnórsson, S., Sigurdsson, S., Svarvarsson, H., 1982. The chemistry of geothermal waters in Iceland. I. Calculation of aqueous speciation from $0^{\circ}$ to $370^{\circ} \mathrm{C}$. Geochim. Cosmochim. Acta 46, 1513-1532.

Bickle, M., Chadwick, A., Huppert, H.H., Hallworth M., Lyle S., 2007. Modelling carbon dioxide accumulation at Sleipner: Implications for underground carbon storage. Earth Planet. Sci. Lett. 255, 1-2, 15, 164-176.

Brown, C. A., Comoton, R. G., Narramore, C. A., 1993. The kinetics of calcite dissolution /precipitation. J. Colloid Interface Sci. 160, 372-379.

Carrier, W.D., 2003. Goodbye, Hazen; Hello, Kozeny-Carman. J. Geotech. Geoenviron. Engin. $129,11,1054-1056$.

Chiba, H., 1991. Attainment of solution and gas equilibrium in Japanese geothermal systems. Geochem. J. 25, 335-355.

Gales, C., Shane, $\mathrm{H} ., 1905$. About a case of kaolinitisation in granite by a cold $\mathrm{CO}_{2}$ bearing water. Zenlt. Geol. Min. Palisant. 427-467.

Gruesbeck, C., Collins, R.E., 1982. Entrainment and deposition of fine particles in porous media. Soc. Petrol. Engin. J. 22, 6, 847-856.

Gunter, W.D., Bird, G.W., 1988. $\mathrm{CO}_{2}$ production in tar sand reservoirs under in situ steam temperatures: Reactive calcite dissolution. Chem. Geol. 70, 301-311.

IPCC, 2005. Underground geological storage. In: IPCC Special Report on Carbon Dioxide Capture and Storage, 195-276.

Ives, K.J., 1975. Mathematical models of deep bed filtration. NATO Advanced Study Institute Ser. E. Applied Sciences. 2, 203-224.

Jonasson, R.G., Rispler, K., Wiwchar, B., Gunter, W.D., 1996. Effect of phosphonate inhibitors on calcite nucleation kinetics as a function of temperature using light scattering in an autoclave. Chem. Geol. 132, 215-225.

Kaieda, H., Ito, H., Kiho, K., Suzuki, K., Suenaga, H., Shin, K., 2005. Review of the Ogachi HDR Project in Japan. Proc. World Geothermal Congress. 1601.

Kim, J.S., Lee I.M., Jang J.H., Choi H.S., 2009. Groutability of cement-based grout with consideration of viscosity and filtration phenomenon. Internat. J. Numer. Anal. Geomech. 33, 1771-1797.

Kuroda, Y., Yamada, Y., Ueda, A., Matsuoka, T., Yamada, N., 2009. Experimental research of plagioclase (rock)-gas-water interaction at hydrothermal conditions for $\mathrm{CO}_{2}$ mineralization. Jap. Mag. Mineral. Petrol. Sci. 38, 111-121.

Lee, Y.J., Morse, J.W., Wiltschko D.V., 1996. An experimentally verified model for calcite precipitation in veins. Chem. Geol. 130, 203-215.

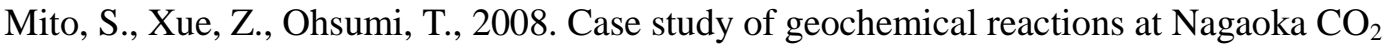
injection site, Japan. Internat. J. Greenhouse Gas Control 2. 309-318.

Ozawa, A., Ueda, A., Nishimura, Y., Sato, H., Tsukamoto, K., 2006. Geochemical monitoring of calcite precipitation and dissolution in Ca rich ground waters with a newly developed 
interferometer. Abstract $19^{\text {th }}$ General Meeting of the International Mineralogical Association, 168.

Parkhurst, D.L., Appelo, C.A.J., 1999. Users Guide to PHREEQC (Version 2) - A computer program for speciation, batch-reaction, one-dimensional transport, and inverse geochemical calculations. U. S. Geol. Surv. Water-Resour. Invest. Rep. 99-4259.

RITE, 2008. Development of a technology for $\mathrm{CO}_{2}$ fixation and sequestration using serpentinite rock mass. Annual report. 184.

Shikazono, N., Harada, H., Ikeda, N., Kashiwagi, H., 2009. Dissolution of basaltic rocks and its application to understand sequestration of $\mathrm{CO}_{2}$-Estimate of mineral trapping by dissolution-precipitation simulation. J. Miner. Soc. Jap. 38, 149-160.

Shiraki, R., Brantley, S.L., 1995. Kinetics of near-equilibrium calcite precipitation at $100{ }^{\circ} \mathrm{C}$ : An evaluation of elementary reaction-based and affinity-based rate laws. Geochim. Cosmochim. Acta. 59, 8, 1457-1471.

Teng, H.H., Dove, P.M., Yoreo, J.J., 2000. Kinetics of calcite growth: Surface processes and relationships to macroscopic rate laws. Geochim. Cosmochim. Acta. 64, 2255-2266.

Ueda, A., Kato, K., Ohsumi, T., Yajima, T., Ito, H., Kaieda, H., Metcalf, R., Takase, H., 2005. Experimental studies of $\mathrm{CO}_{2}$-rock interaction at elevated temperatures under hydrothermal conditions. Geochem. J. 39, 417-425.

$\mathrm{Xu}, \mathrm{T}$., Apps, J.A., Pruess, K., 2004. Numerical simulation of $\mathrm{CO}_{2}$ disposal by mineral trapping in deep aquifers. Appl. Geochem. 19, 917-936.

Zhang, Y., Dawe, R.A., 2000. Influence of $\mathrm{Mg}^{2+}$ on the kinetics of calcite precipitation and calcite crystal morphology. Chem. Geol. 163, 129-138. 


\section{Figure and Table captions}

Fig. 1 Experimental setup for the column test (a) at room temperature and (b) at high temperature.

Fig. 2 Conservation of mass for the one-dimensional transport process in the advection reaction.

Fig. 3 Procedure for numerical calculation in the geochemical clogging model.

Fig. 4 Numerical calculation results for the Namikata case at room temperature $\left(T=20.2{ }^{\circ} \mathrm{C}\right)$.

(a) Flow rate, (b) Total head, (c) Pore fluid velocity, and (d) Ratio of filtration coefficient to pore fluid velocity (e) Porosity (f) and Supersaturated concentration of $\mathrm{Ca}^{2+}$

Fig. 5 Numerical calculation results for the Ogachi case at high temperature $\left(T=185^{\circ} \mathrm{C}\right)$.

(a) Flow rate, (b) Total head, (c) Pore fluid velocity, and (d) Ratio of filtration coefficient to pore fluid velocity (e) and Porosity (f) Supersaturated concentration of $\mathrm{Ca}^{2+}$

Fig. 6 Comparison of amount of deposited total $\mathrm{Ca}$

(a) with respect to distance from the inlet. (b) with respect to elapsed time for the Namikata case.

(c) with respect to elapsed time for the Ogachi case.

Fig. 7 Comparison of normalized intrinsic permeability

(a) with respect to distance from the inlet. (b) with respect to elapsed time for the Namikata case.

(c) with respect to elapsed time for the Ogachi case.

Table 1 Chemical composition of fluid samples.

Table 2 Properties used for numerical calculation. 
Fig. 1

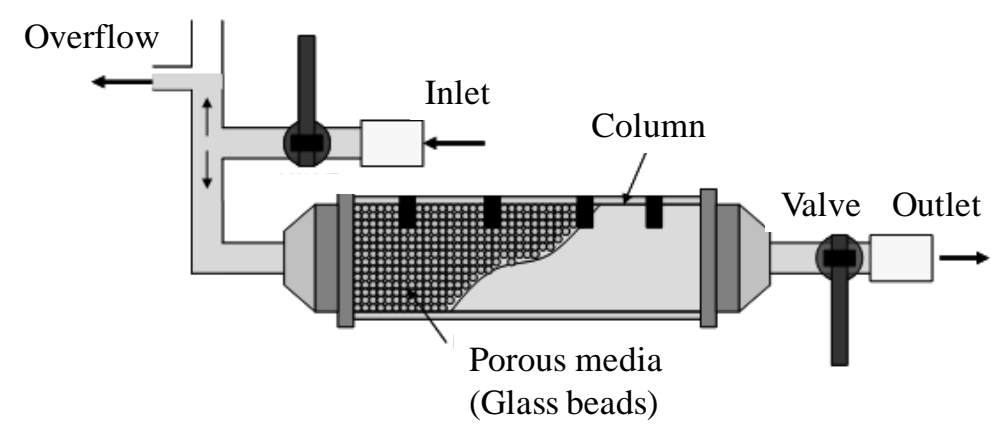

(a)

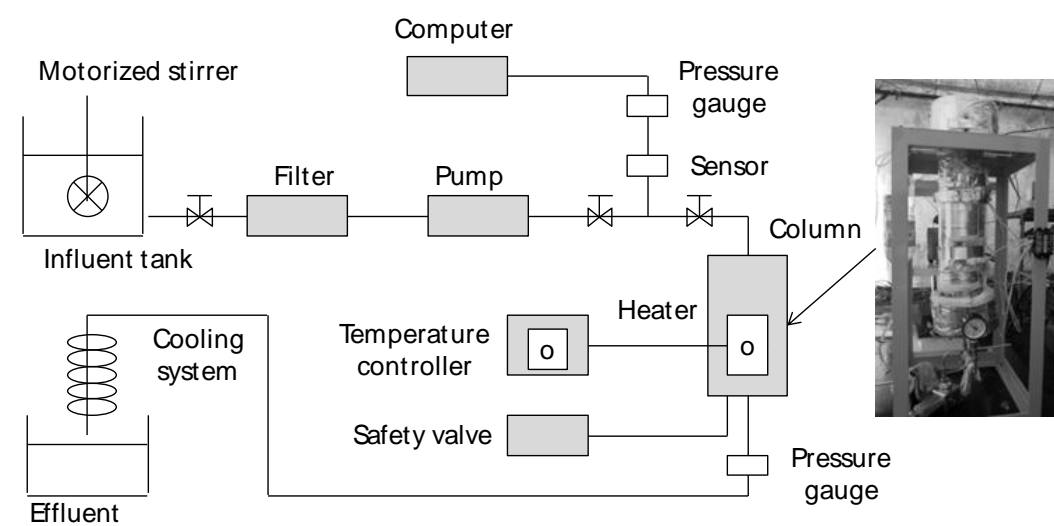

tank

(b) 
1

2

3

4

5

6

7

8

9

10

11

12

13

14

15

16

17

18

19

20

21

22

23

24

25

26

27

28

29

30

31

32

33

34

35

36

37

38

39

40

41

42

43

44

45

46

47

48

49

50

51

52

53

54

55

56

57

58

59

60

61

62

63

64

65

Fig. 2

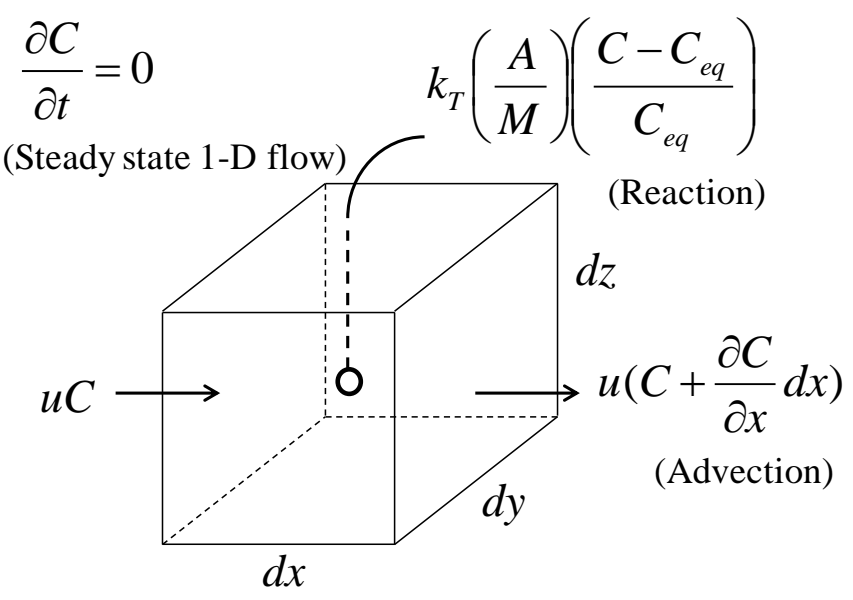




\section{Fig. 3}

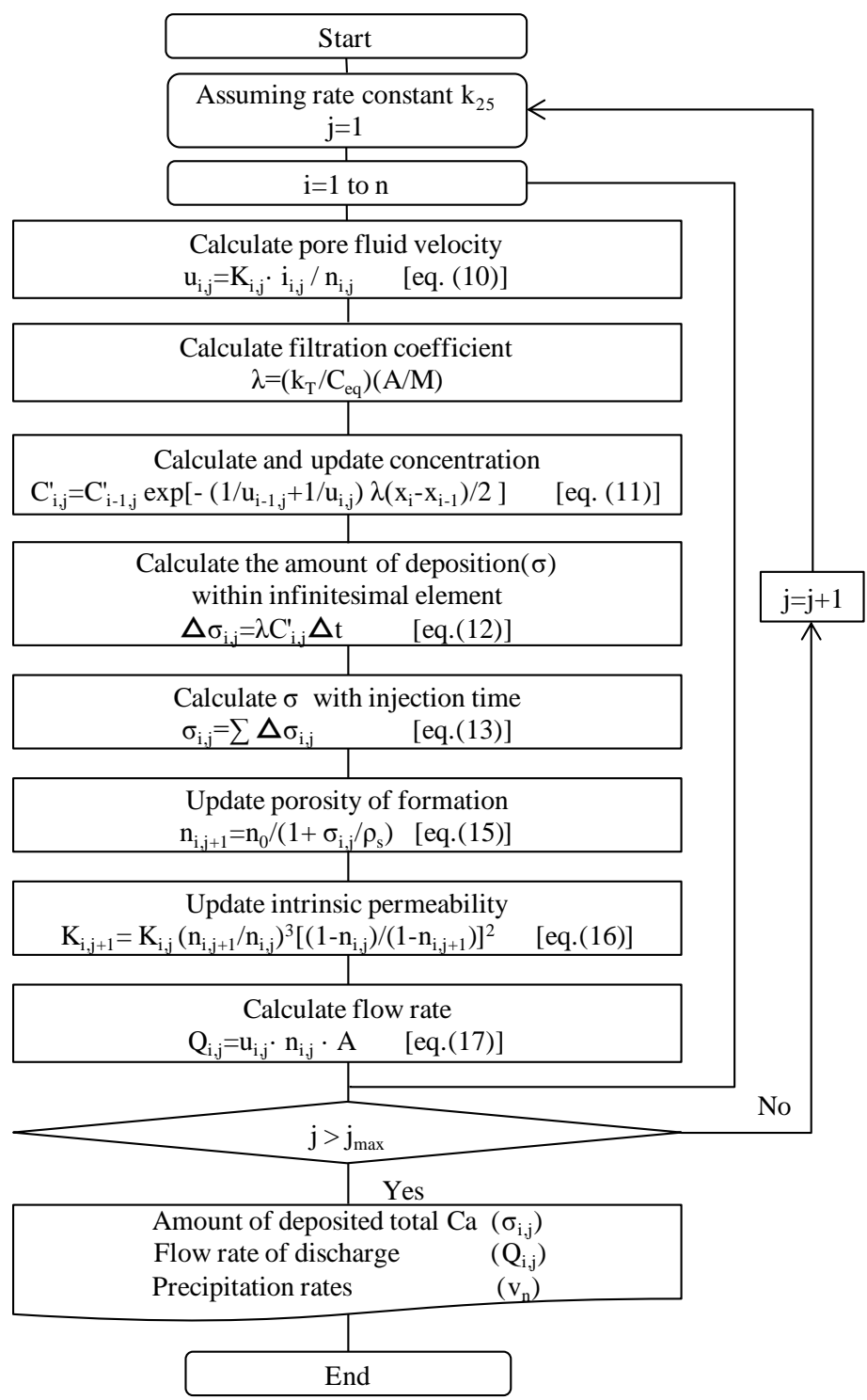


1
Fig. 4

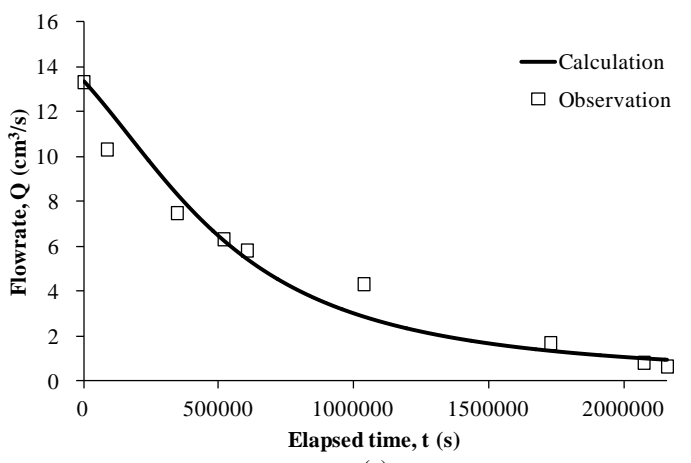

(a)

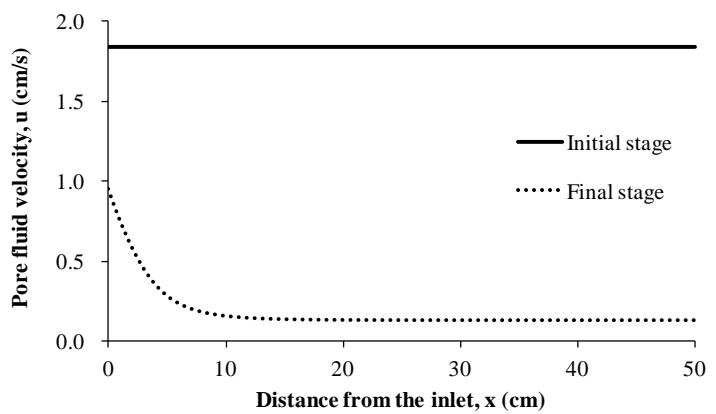

(c)

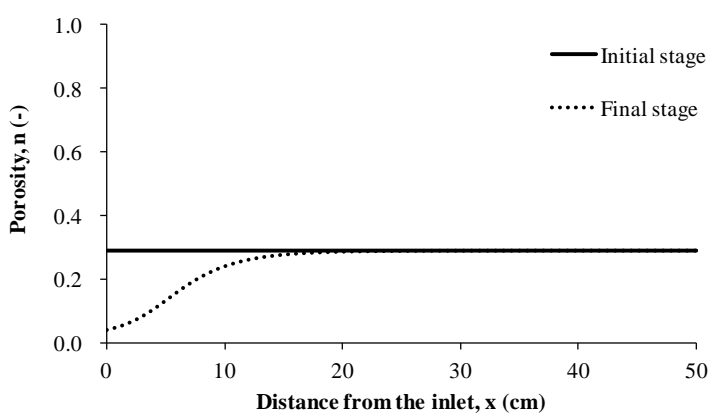

(e)

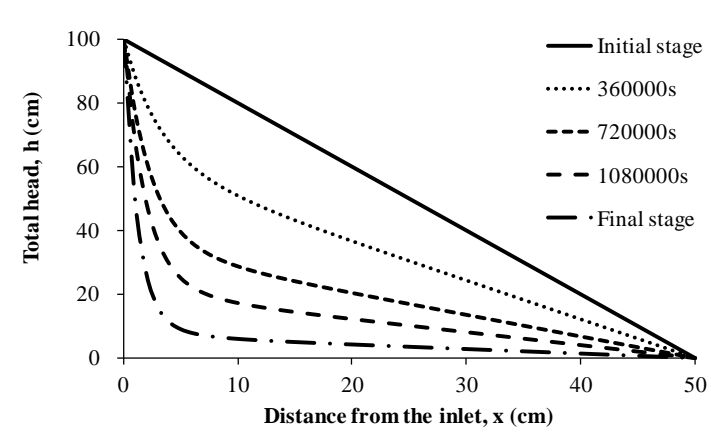

(b)

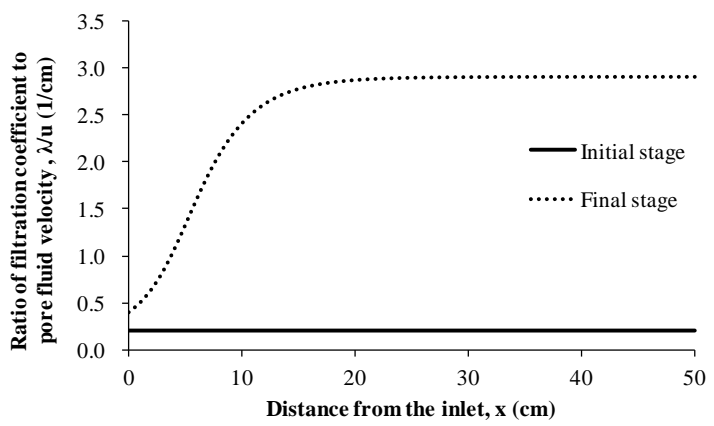

(d)

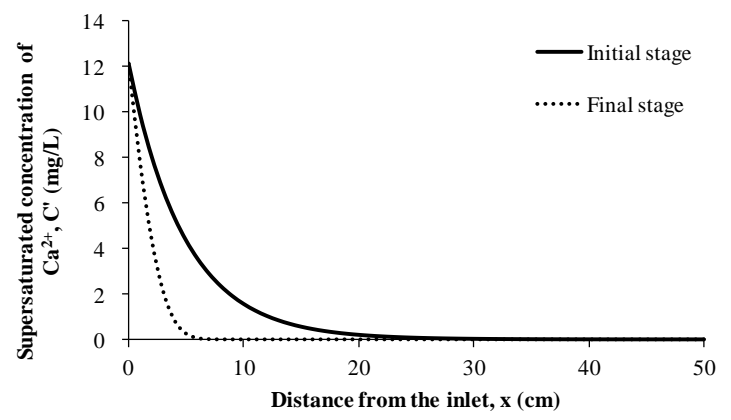

(f) 
1
Fig. 5
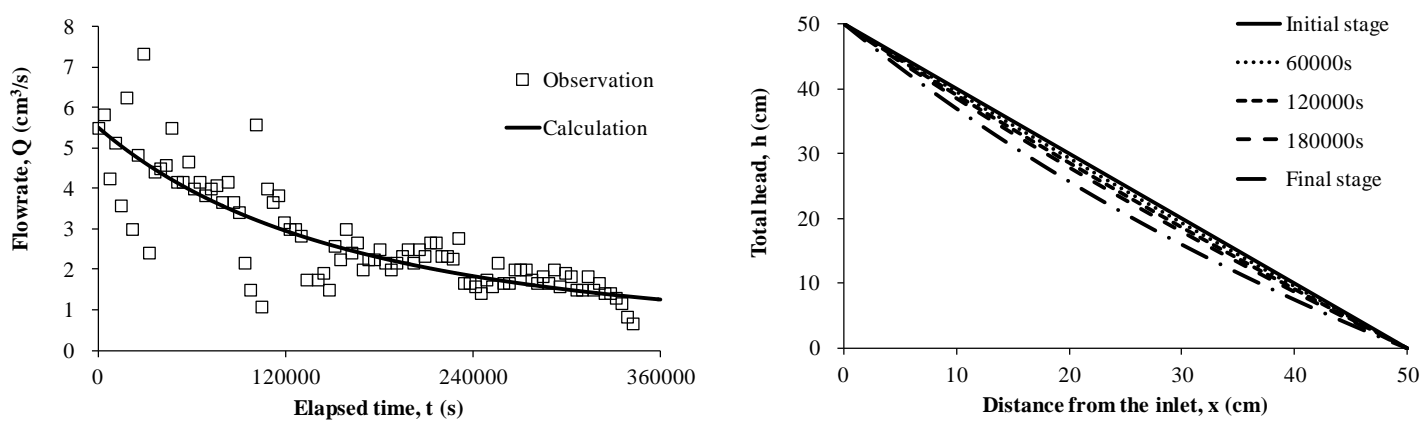

(a)

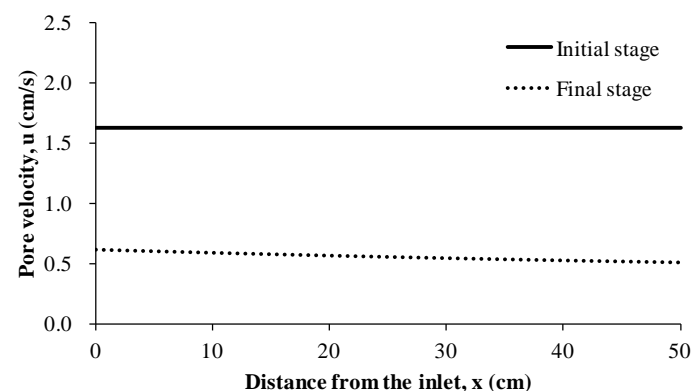

(c)

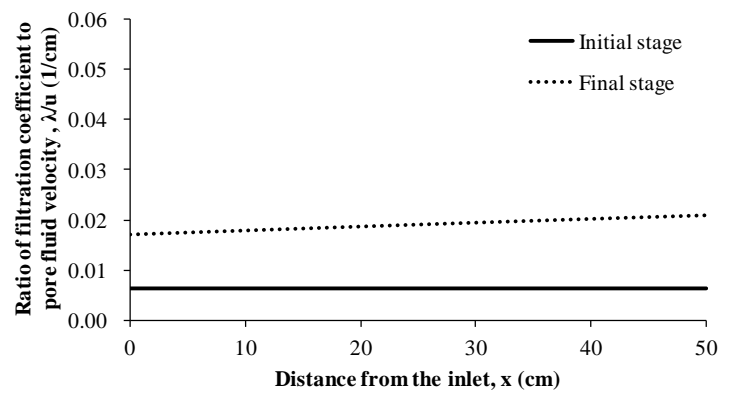

(d)

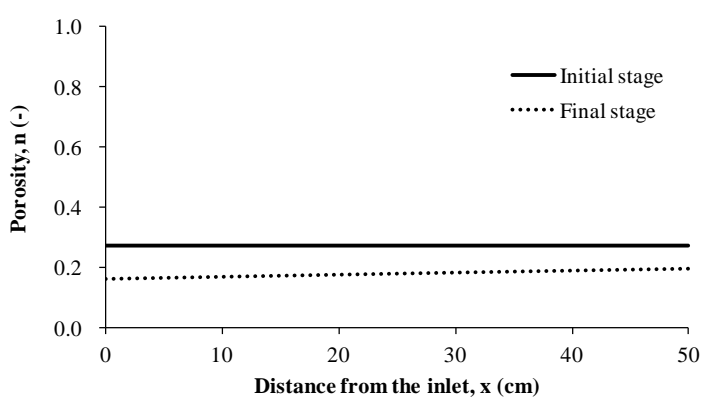

(e)

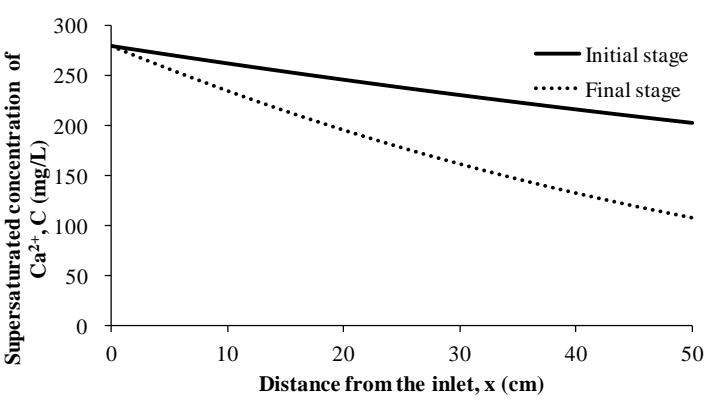

(f) 
1

2

3

4

5

6

7

8

9

10

11

12

13

14

15

16

17

18

19

20

21

22

23

24

25

26

27

28

29

30

31

32

33

34

35

36

37

38

39

40

41

42

43

44

45

46

47

48

49

50

51

52

53

54

55

56

57

58

59

60

61

62

63

64

65

Fig. 6

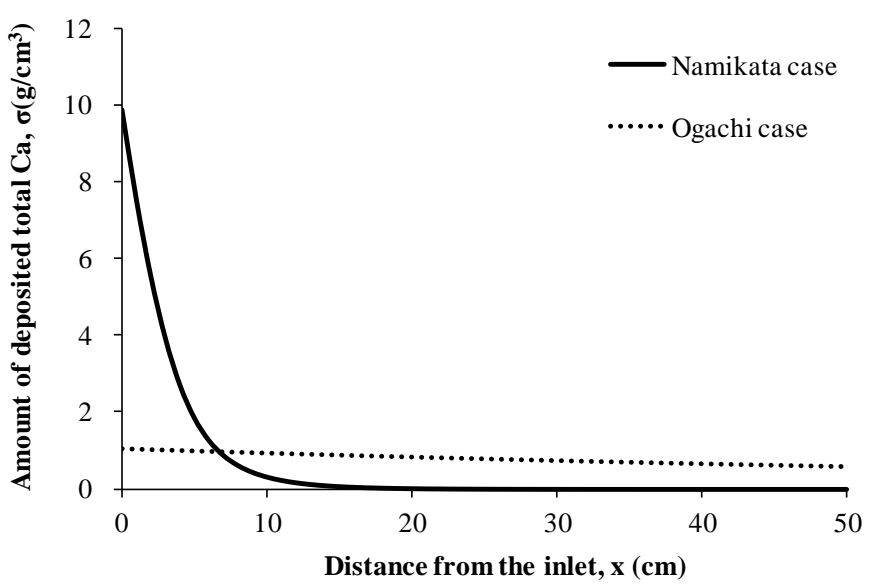

(a)

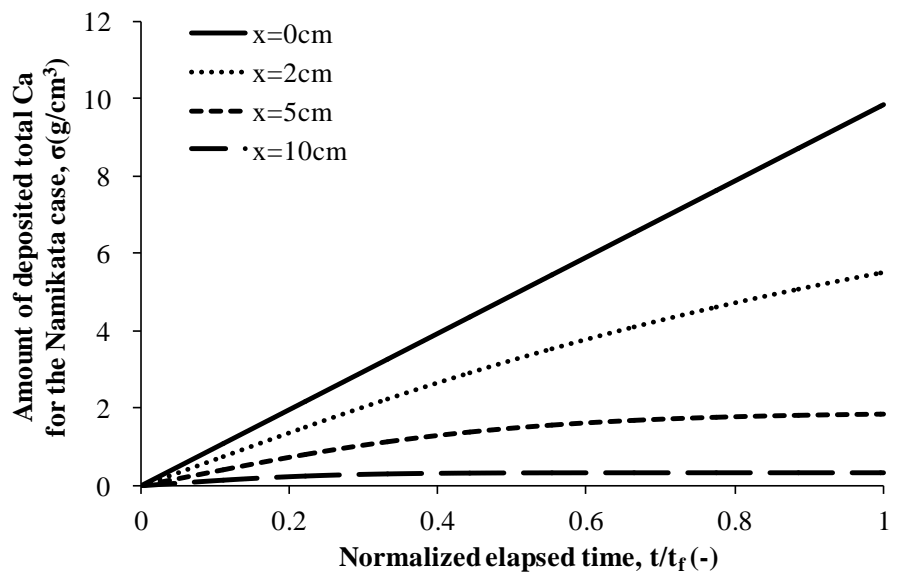

(b)

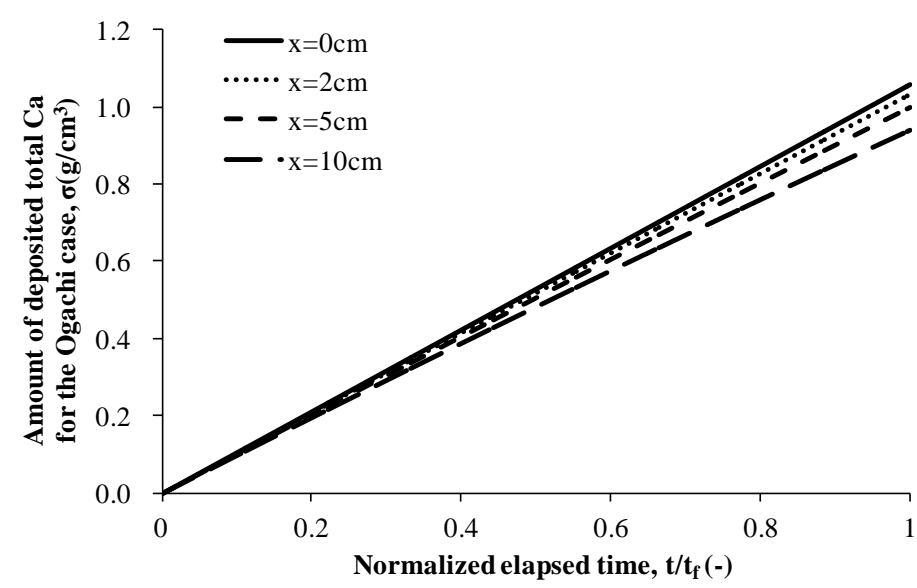

(c) 
1

Fig. 7

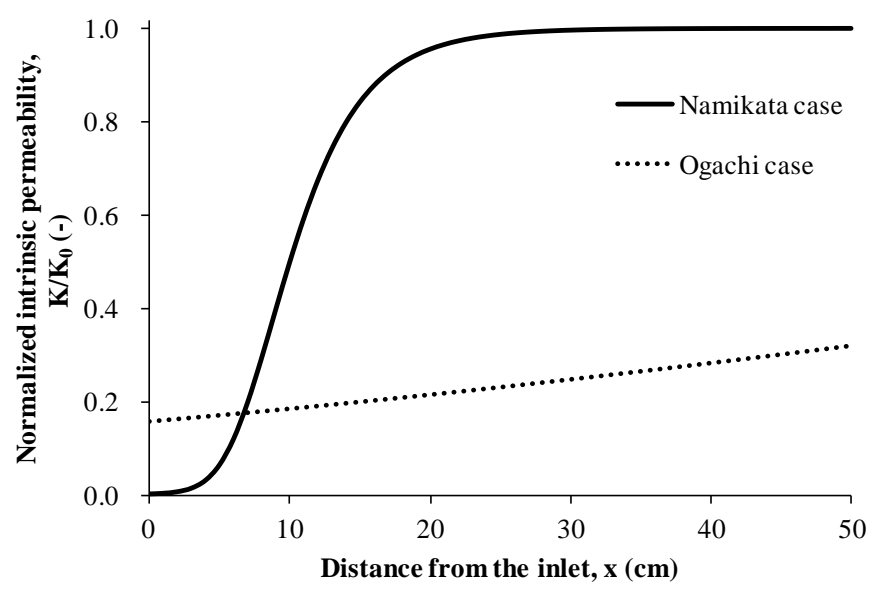

(a)

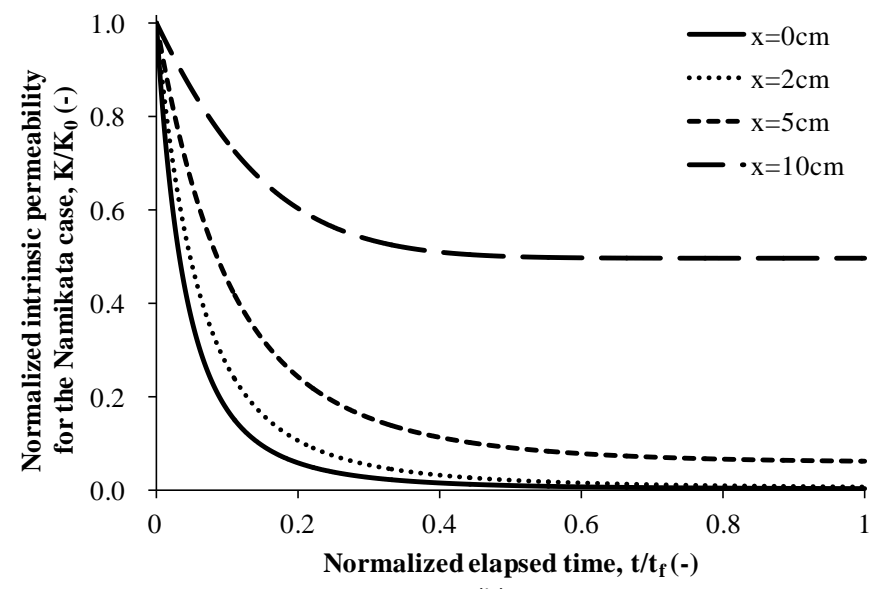

(b)

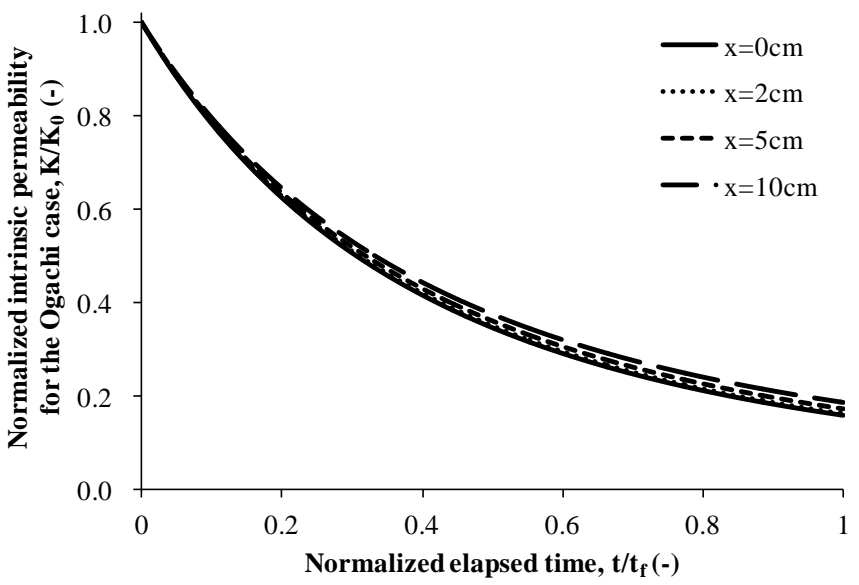

(c) 
1
Table 1

\begin{tabular}{|c|c|c|}
\hline Chemical composition of fluid samples & For the Namikata case & For the Ogachi case \\
\hline Date of observation & 2009.10 .24 & 2010.10 .16 \\
\hline Temperature of fluid $\left({ }^{\circ} \mathrm{C}\right)$ & 20.2 & 15.1 \\
\hline $\mathrm{pH}$ (measured by $\mathrm{pH}$ meter) & 11.3 & 6.2 \\
\hline $\mathrm{EC} \quad(\mathrm{mS} / \mathrm{m})$ & 46 & 249 \\
\hline S.I. of calcite & $1.1\left(\right.$ at $\left.20.2^{\circ} \mathrm{C}\right)$ & $\begin{array}{c}-0.38\left(\text { at } 15.1^{\circ} \mathrm{C}\right) \\
\left.1.8 \quad \text { (at } 185^{\circ} \mathrm{C}\right)\end{array}$ \\
\hline $\mathrm{Na} \quad(\mathrm{mg} / \mathrm{L})$ & 47 & 190 \\
\hline $\mathrm{K} \quad(\mathrm{mg} / \mathrm{L})$ & 2 & 0.5 \\
\hline $\mathrm{Ca} \quad(\mathrm{mg} / \mathrm{L})$ & 18 & 280 \\
\hline $\mathrm{Mg}(\mathrm{mg} / \mathrm{L})$ & 0.2 & 0.6 \\
\hline $\mathrm{Cl} \quad(\mathrm{mg} / \mathrm{L})$ & 66 & 550 \\
\hline $\mathrm{SO}_{4}(\mathrm{mg} / \mathrm{L})$ & 7.5 & 9 \\
\hline $\mathrm{SiO}_{2} \quad(\mathrm{mg} / \mathrm{L})$ & 12 & 28 \\
\hline Al $\quad(\mathrm{mg} / \mathrm{L})$ & 0.8 & 0.1 \\
\hline $\mathrm{Fe} \quad(\mathrm{mg} / \mathrm{L})$ & 0.007 & 5.2 \\
\hline $\mathrm{Mn}(\mathrm{mg} / \mathrm{L})$ & $<0.001$ & 0.07 \\
\hline $\mathrm{CO}_{2}(\mathrm{mg} / \mathrm{L})$ & 13 & 620 \\
\hline
\end{tabular}


1

Table 2

\begin{tabular}{l|cc}
\hline Properties for numerical calculation & Namikata case & Ogachi case \\
\hline Density of deposited $\mathrm{Ca}, \rho_{s}\left(\mathrm{~g} / \mathrm{cm}^{3}\right)$ & 1.55 & 1.55 \\
Density of porous material, $\rho_{m}\left(\mathrm{~g} / \mathrm{cm}^{3}\right)$ & 2.50 & 2.66 \\
Density of fluid, $\rho_{f}\left(\mathrm{~g} / \mathrm{cm}^{3}\right)$ & 0.998 & 0.882 \\
Initial porosity, $n_{0}(-)$ & 0.29 & 0.27 \\
Initial flow rate, $Q_{0}\left(\mathrm{~cm}^{3} / \mathrm{s}\right)$ & 13.3 & 5.5 \\
Initial intrinsic permeability, $K_{0}(\mathrm{~cm} / \mathrm{s})$ & 0.27 & 0.44 \\
Specific reactive surface area, $A / M\left(\mathrm{~cm}^{2} / \mathrm{g}\right)$ & 9.8 & 9.8 \\
Specific reactive surface area, $S\left(=\rho_{f}(A / M)\right)\left(\mathrm{cm}^{-1}\right)$ & 9.78 & 8.64 \\
Unit distance, $\Delta x(\mathrm{~cm})$ & 1 & 1 \\
Differential time, $\Delta t(\mathrm{~s})$ & 360 & 60 \\
Total head of inlet, $h_{0}(\mathrm{~cm})$ & 100 & 50 \\
Total head of outlet, $h_{L}(\mathrm{~cm})$ & 0 & 0 \\
Hydraulic gradient, $i(-)$ & 2 & 1 \\
Initial concentration of $\mathrm{Ca}{ }^{2+}, C_{i}\left(\mathrm{~g} / \mathrm{cm}^{3}\right)$ & $1.8 \times 10^{-5}$ & $2.8 \times 10^{-4}$ \\
Equilibrium concentration of $\mathrm{Ca}^{2+}, C_{e q}\left(\mathrm{~g} / \mathrm{cm}^{3}\right)$ & $5.9 \times 10^{-6}$ & $2.6 \times 10^{-7}$ \\
Supersaturated concentration of $\mathrm{Ca}^{2+}, C_{i}{ }^{\prime}\left(=\mathrm{C}_{\mathrm{i}}-\mathrm{C}_{\mathrm{eq}}\right)\left(\mathrm{g} / \mathrm{cm}^{3}\right)$ & $1.2 \times 10^{-5}$ & $2.8 \times 10^{-4}$ \\
Temperature of fluid, $T\left({ }^{\circ} \mathrm{C}\right)$ & 20.2 & 185 \\
Activation energy, $E_{a}(\mathrm{~kJ} / \mathrm{mol})$ & 41.87 & 41.87 \\
Rate constant at $25^{\circ} \mathrm{C}, k_{25}\left(\mathrm{~mol} / \mathrm{m}^{2} / \mathrm{s}\right)$ & $3.0 \times 10^{-5}$ & $1.0 \times 10^{-10}$ \\
Rate constant at $T^{\circ} \mathrm{C}, k_{T}\left(\mathrm{~mol} / \mathrm{m}^{2} / \mathrm{s}\right)$ & $2.3 \times 10^{-5}$ & $3.65 \times 10^{-8}$ \\
Precipitation rate of calcite, $v_{n}\left(=k_{T} / C_{e q}\right)\left(\mathrm{cm}^{3} / \mathrm{s}\right)$ & $3.9 \times 10^{-2}$ & $1.22 \times 10^{-3}$ \\
Filtration coefficient, $\lambda\left(\mathrm{s}^{-1}\right)$ & 0.38 & 0.011 \\
\hline
\end{tabular}

